\title{
Colocid Dye - A Potential Corrosion Inhibitor for the Corrosion of Mild Steel in Acid Media
}

\author{
Vadivel Sivakumar $^{a *}$, Kaithamalai Velumani ${ }^{a}$, Subramaniam Rameshkumar ${ }^{a}$ (D) \\ ${ }^{a}$ Department of Chemistry, Sri Vasavi College, Erode, TamilNadu, India
}

Received: January 30, 2017; Revised: January 19, 2018; Accepted: March 15, 2018

\begin{abstract}
Corrosion inhibition nature of Colocid dye on the corrosion of mild steel in acid media was analyzed using weightloss and electrochemical methods. The results of electrochemical and weightloss studies indicated that Colocid acid could act as a potential inhibitor for mild steel in acid media. It has been observed that the inhibition efficiency increases with inhibitor concentration and the inhibition efficiency of Colocid acid dye for the corrosion of mild steel in $1.0 \mathrm{M} \mathrm{HCl}$ solution is larger than that in $0.5 \mathrm{M} \mathrm{H}_{2} \mathrm{SO}_{4}$ solution.Potentiodynamic polarization studies showed that the dye molecule is of mixed type inhibitor. The adsorption of the compound on the mild steel surface obeyed Langmuir adsorption isotherm. The potential of zero charge was measured to find corrosion inhibition mechanism in these media.
\end{abstract}

Keywords: Colocid acid dye, Corrosion inhibition, Electrochemical Impedance Spectroscopy, Adsorption isotherm, Potential of zero charge.

\section{Introduction}

The reaction of metals with their environment causes corrosion. The corrosion behavior of metal is due to its natural tendency to combine with chemical elements in their environment to return to its lowest energy state. The phenomenon corrosion is always linked with an environment. The corrosion behavior of a material cannot be described unless the environment in which the material is to be exposed is identified. Similarly, the corrosivity or aggressiveness of an environment cannot be described unless the material that is to be exposed to that environment is identified ${ }^{1}$. The general relation existing among the rate of corrosion, the corrosivity of the environment, and the corrosion resistance of a material is ${ }^{1}$ : $\frac{\text { corrosivity of the environment }}{\text { corrosion resistance of the metal }} \simeq$ rate of corrosive attack

Mild steel is one of the most widely used material in many industries. Excessive corrosion attack is known to occur on mild steel surfaces deployed in service in aqueous acidic environments ${ }^{2}$. In industries acid solutions are often used for cleaning, descaling and pickling of steel structures ${ }^{3}$. Moreover, metal corrosion in acid medium is a serious environmental problem in the oil, fertilizer, metallurgical and other industries ${ }^{4}$. Hence, corrosion control becomes an essential issue from application point of view and it has been reported that inhibitors are needed to be used which act as a barrier to reduce the aggressiveness of the environments against the corrosion attack ${ }^{5,6}$. Organic compounds, which contain polar functional groups with nitrogen, oxygen, and/or sulfur in conjugated systems in their molecules, are generally used as corrosion inhibitors for the reduction of corrosion rate of metals in acid media ${ }^{7-13}$. Studies on corrosion inhibition performance of dyes have shown that organic dyes are quiet effective in retarding the corrosion of mild steel and aluminium in acid or base environments ${ }^{14-24}$. Hence, an attempt has been made to use an organic dye, as corrosion inhibitor for corrosion of mild steel in acid media and thus, the present study describes corrosion inhibition performance of an organic dye, Colocid acid (Figure 1), on corrosion of mild steel in acid media using weight loss, electrochemical impedance and potentiodynamic polarization methods. From the structure of this dye molecule it can be seen that it satisfies almost all the properties of a good corrosion inhibitor. It has large molecular surface area, many aromatic benzenoid rings through which the $\pi$ electrons can interact with metal $\mathrm{d}$ orbitals, hetero atoms such as $\mathrm{N}, \mathrm{O}$ and $\mathrm{S}-$ which are more electron pair donating atoms to the vacant $\mathrm{d}$ orbitals of surface Fe atoms. The corrosion inhibition mechanism of the dye is also explained using adsorption isotherm and potential of zero charge studies in acid media.

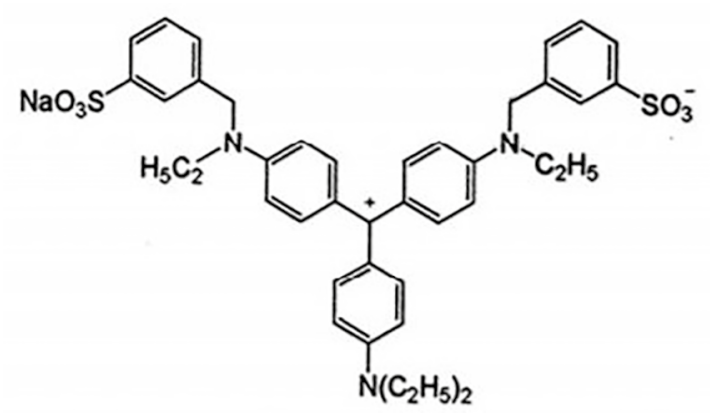

Figure 1. Structure of Colocid acid dye 


\section{Materials and Methods}

\subsection{Materials}

Mild steel specimens of dimensions $2.5 \mathrm{cmX} 1.0 \mathrm{cmX} 0.1$ $\mathrm{cm}$ with the composition $0.084 \% \mathrm{C}, 0.037 \% \mathrm{Mn}, 0.026 \%$ $\mathrm{P}, 0.021 \% \mathrm{~S}$ and rest being $\mathrm{Fe}$ were used for weight loss studies. The specimens were polished well with the emery sheets of grade $1 / 0$ to $5 / 0$ and then washed thoroughly in double distilled water. Finally, the specimens were degreased with acetone and immersed in acid solutions after weighing. A Teflon coated cylindrical mild steel rod having the same composition of mild steel specimen with an exposed area of $0.1963 \mathrm{~cm}^{2}$ was used for electrochemical studies. Colocid acid purchased from ZAUBA was used as such without further purification. All the acid solutions used for studies are of analytical grade and double distilled water was used for preparing all solutions.

\subsection{Weight loss measurements}

According to ASTM procedure weight loss studies were carried out ${ }^{25}$. Mild steel specimens in triplicate were immersed in $100 \mathrm{~mL}$ of the acid solutions with and without inhibitor for two hours and the average weight loss of three specimens were used to calculate the corrosion inhibition efficiency. The weight loss studies have been carried out at room temperature $(300 \pm 1 \mathrm{~K})$. The corrosion inhibition efficiency was calculated using the expression;

$$
\mathrm{IE} \%=\frac{\mathrm{w}_{1}-\mathrm{w}_{2}}{\mathrm{w}_{1}} \times 100
$$

Where, $\mathrm{W}_{1}$ and $\mathrm{W}_{2}$ are weight loss of mild steel specimens in the absence and presence of inhibitor respectively in the acid media.

\subsection{Electrochemical impedance measurements}

Electrochemical Impedance measurements were carried out using a potentiostat "GAMRY REFERENCE 3000". The impedance spectra were recorded using a three electrode set up, in which a Pt foil served as counter electrode and Saturated Calomel Electrode served as reference electrode. A Teflon coated cylindrical mild steel rod was used as working electrode. Before recording impedance spectra, a stabilization period of 45 minutes was given after immersing the working electrode in acid solutions, to attain the stationary corrosion potential. The impedance spectra were recorded at the AC sinusoidal potential of amplitude $10 \mathrm{mV}$ in the frequency range $100 \mathrm{kHz}-100 \mathrm{mHz}$. The double layer capacitance and charge transfer resistance values were evaluated from the impedance spectra using standard procedures ${ }^{26}$. The corrosion inhibition efficiency was calculated using the expression;

$$
\mathrm{IE} \%=\frac{R_{c t}^{\prime}-R_{c t}}{R_{c t}^{\prime}} \times 100
$$

Where $R_{c t}^{\prime}$ and $R_{c t}$ are charge transfer resistance values in the presence and absence of inhibitor respectively in the acid media.

\subsection{Potentiodynamic polarization measurements}

Potentiodynamic polarization measurements had been carried out using the same cell setup employed in Electrochemical Impedance studies. The potentials were swept primarily from more negative potential than $\mathrm{E}_{\mathrm{OCP}}$ (Open Circuit Potential) to more positive potential than $\mathrm{E}_{\mathrm{OCP}}$ through equilibrium corrosion potential at a scan rate of $1.67 \mathrm{mV} / \mathrm{s}$. The inhibition efficiency of the dye on the corrosion of mild steel in acid media was calculated employing the formula,

$$
\mathrm{IE} \%=\frac{i_{\text {corr }}-i_{\text {corr }}^{\prime}}{i_{\text {corr }}} \times 100
$$

Where, $i_{\text {corr }}$ and $i_{\text {corr }}$ are corrosion current density values in the absence and presence of inhibitor respectively in the acid media.

\subsection{Measurement of potential of zero charge}

The electrochemical impedance spectra were recorded for blank and inhibited acid solutions at the fixed frequency $(100 \mathrm{~Hz})$ at different applied DC potentials. The double layer capacitance values so obtained are then plotted against applied DC potential to find potential of zero charge (PZC).

\subsection{Scanning Electron Micrograph}

Surface morphologies of corroded metal surfaces in the acid media in the presence and absence of inhibitor molecules were studied, using a digital Scanning Electron Microscope model SU6600 with an accelerating voltage of $22.0 \mathrm{kV}$, at a scan speed-Slow 5 and calibration scan speed of 25 . All micrographs of the specimen were taken at a magnification of 500X. Before taking SEM images the mild steel specimen were immersed in acid solutions with and without inhibitor for two hours.

\section{Results and Discussion}

\subsection{Results of weight loss measurement}

The corrosion inhibition efficiency values of inhibitor in acid media,calculated from the weight loss data, are presented in Table 1. The corrosion inhibition efficiency increased with inhibitor concentration in the acid media. This implies that there is an interaction between inhibitor molecules and metal surface in acid media and led to adsorption of inhibitor onto the metal surface. The increase in inhibitor efficiency with inhibitor concentration can be attributed to the increase in adsorption with inhibitor concentration in the acid media. Adsorption of inhibitor molecules onto the metal surface separates the metal surface from corrosive media ${ }^{27}$ and reduce corrosion rate. 
Table 1. Corrosion inhibition Efficiency values calculated from the weight loss measurements

\begin{tabular}{cccc}
\hline Medium & $\begin{array}{c}\text { Inhibitor } \\
\text { concentration } \\
(\mathrm{ppm})\end{array}$ & $\begin{array}{c}\text { Corrosion } \\
\text { rate (mpy) }\end{array}$ & $\begin{array}{c}\text { Inhibition } \\
\text { efficiency } \\
(\text { IE\%) }\end{array}$ \\
\hline \multirow{7}{*}{$1 \mathrm{MHCl}$} & 5 & 169.0 & - \\
& 10 & 99.37 & 41.2 \\
& 20 & 79.26 & 47.1 \\
& 50 & 65.40 & 53.1 \\
& 100 & 32.11 & 61.3 \\
& 200 & 26.87 & 81.0 \\
& 400 & 20.52 & 87.8 \\
& 600 & 18.08 & 89.3 \\
\hline \multirow{6}{*}{$0.5 \mathrm{M} \mathrm{H}_{2} \mathrm{SO}_{4}$} & Blank & 522.7 & - \\
& 5 & 395.7 & 24.3 \\
& 10 & 226.8 & 56.6 \\
& 20 & 192.8 & 63.1 \\
& 50 & 167.7 & 67.9 \\
& 100 & 125.9 & 75.9 \\
& 200 & 91.47 & 82.5 \\
& 400 & 83.11 & 84.1 \\
& 600 & 68.47 & 86.9 \\
\hline
\end{tabular}

\subsection{Electrochemical impedance spectroscopic studies}

The corrosion response of mild steel in the presence and absence of the inhibitor in $1.0 \mathrm{M} \mathrm{HCl}$ and $0.5 \mathrm{M} \mathrm{H}_{2} \mathrm{SO}_{4}$ solutions have been investigated using electrochemical impedance spectroscopy at $27 \pm 1^{\circ} \mathrm{C}$ and the corresponding Nyquist plots are shown in Figure 2.

The Nyquist plots obtained are simple semi circles, free from inductive loops. The simple - R(CR) - model best describes metal/solution interface. However the complex planes obtained are depressed semi circles, indicating a non-ideal capacity behavior of this interface ${ }^{28,29}$. This capacitance dispersion at the interfaces can be attributed to the surface roughness, the degree of polycrystallinity, the chemical inhomogeneities and anion adsorption ${ }^{28,30}$. A precise modeling for this situation is done by introducing a constant phase element (CPE) in the place of capacitor ${ }^{28,30}$ and the corresponding equivalent circuit is shown in Figure 3.

The electrochemical impedance parameters obtained for the corrosion of mild steel in these two acid media in the presence and absence of the inhibitor by using the approximated equivalent circuits are shown in Table 2. From this table it is seen that with increasing inhibitor concentration both in $1.0 \mathrm{M} \mathrm{HCl}$ and $0.5 \mathrm{M} \mathrm{H}_{2} \mathrm{SO}_{4}$ acid media, the $\mathrm{R}_{\mathrm{ct}}$ values increased while the values of $\mathrm{C}_{\mathrm{dl}}$ decreases which can be calculated using the expression,

$$
C_{d l}=Y_{0} \omega^{n-1}
$$

where ' $\omega$ ' is the angular frequency at the maximum value of the imaginary part of impedance spectrum. The increase in the $R_{c t}$ values with an increase in inhibitor concentration is the result of an increase in the surface coverage of the inhibitor molecules; the increased surface coverage led to an increase in inhibitor efficiency ${ }^{29}$. The decrease in $\mathrm{C}_{\mathrm{dl}}$ values with the increase in inhibitor concentration is due to the adsorption of inhibitor molecules at the metal - solution interface with the replacement of water molecules, which led to the decrease in local dielectric constant and/or an increase in the thickness of electrical double layer ${ }^{31}$. Hence the decrease in $\mathrm{C}_{\mathrm{dl}}$ values caused by the gradual displacement of $\mathrm{H}_{2} \mathrm{O}$ molecules by the adsorption of inhibitor dye molecule at the metal-solution interface decreases the extent of the corrosion ${ }^{32}$.

\subsection{Potentiodynamic polarization studies}

The potentiodynamic polarization curves obtained for mild steel in $1 \mathrm{M} \mathrm{HCl}$ and $0.5 \mathrm{M} \mathrm{H}_{2} \mathrm{SO}_{4}$ solutions in the absence and presence of inhibitor are shown in Figure 4a and $4 \mathrm{~b}$ respectively.

From these figures it is clear that the addition of inhibitor to the corrosive media does not bring about significant changes in the cathodic and anodic slopes. The electrochemical parameters such as corrosion potential $\left(\mathrm{E}_{\text {corr }}\right)$, corrosion current density $\left(\mathrm{i}_{\text {corr }}\right)$ and cathodic and anodic tafel slopes are presented in Table 3.

From Figure 4 it is clear that the addition of inhibitor to the corrosive media shifts both anodic and cathodic curves to a greater extent towards lower current density values compared to blank acid solutions. In both the media the corrosion potential is also shifted to more negative with respect to uninhibited solution to smaller extent with the addition of inhibitor. This indicates the decrease in rate of hydrogen evolution on the mild steel surface due to the adsorption of dye molecules onto the metal surface ${ }^{28,33}$. The shift in corrosion potential is not much larger with the addition of inhibitor. All these indicate that the inhibitor is of mixed type. While scanning the potential in the negative direction (cathodic region) the metal surface is negatively charged and it could attract the positively charged inhibitor molecules. When the potential is scanned in the positive direction the metal surface is positively charged that could attract the negatively charged ions namely anions from acid molecules and this anion can act as a bridge between metal surface and protonated positively charged dye molecules. 

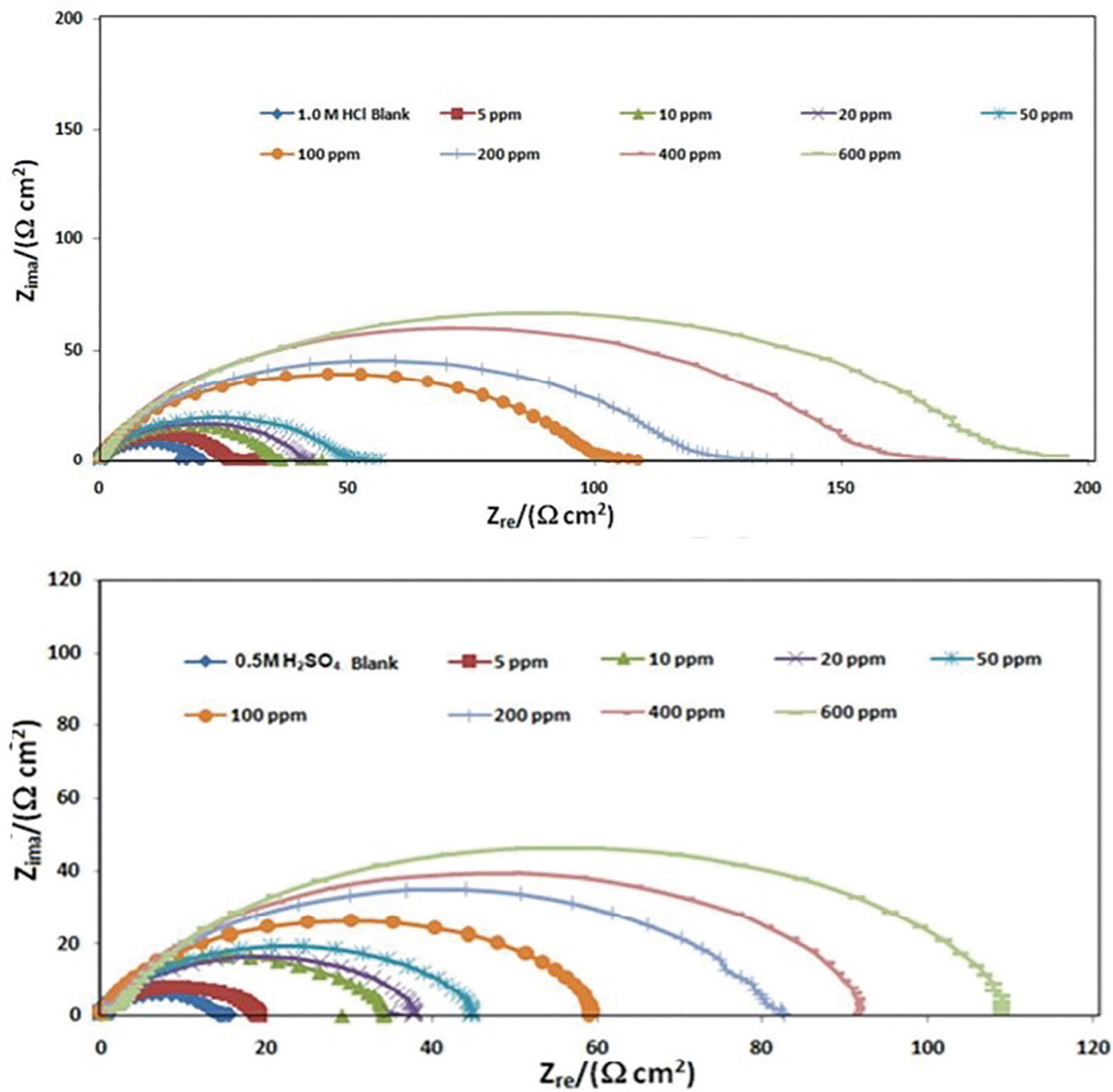

Figure 2. The Nyquist plots for $\mathrm{MS}$ electrode obtained in $1.0 \mathrm{M} \mathrm{HCl}$ and $0.5 \mathrm{M} \mathrm{H}_{2} \mathrm{SO}_{4}$ solutions in the absence and presence of Colocid dye at various concentrations

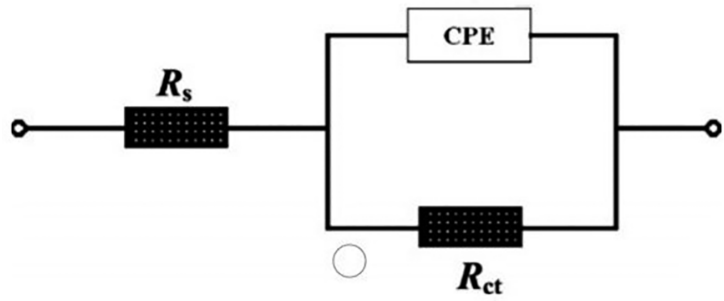

Figure 3. Equivalent circuit for the mild steel surface-corrosive media interface 
Table 2. Electrochemical impedance parameters for $\mathrm{MS}$ in $1.0 \mathrm{M} \mathrm{HCl}$ and $0.5 \mathrm{M} \mathrm{H}_{2} \mathrm{SO}_{4}$ solutions in the presence and absence of inhibitor.

\begin{tabular}{|c|c|c|c|c|c|}
\hline Medium & $\begin{array}{c}\text { Inhibitor } \\
\text { concentration (ppm) }\end{array}$ & Ret $\Omega \mathrm{cm}^{2}$ & $Y_{0}\left(x 10^{-6}\right) \Omega^{-1} \mathrm{~cm}^{-2}$ & $\mathrm{n}$ & Inhibitor Efficiency \\
\hline \multirow{9}{*}{$1.0 \mathrm{MHCl}$} & Blank & 18.8 & 262 & 0.970 & - \\
\hline & 5 & 32.2 & 253 & 0.938 & 41.6 \\
\hline & 10 & 35.7 & 205 & 0.940 & 47.3 \\
\hline & 20 & 40.1 & 176 & 0.967 & 52.9 \\
\hline & 50 & 48.8 & 169 & 0.968 & 61.5 \\
\hline & 100 & 100 & 143 & 0.966 & 81.2 \\
\hline & 200 & 120 & 127 & 0.974 & 84.4 \\
\hline & 400 & 142 & 112 & 0.978 & 86.8 \\
\hline & 600 & 189 & 101 & 0.969 & 90.1 \\
\hline \multirow{9}{*}{$0.5 \mathrm{M} \mathrm{H}_{2} \mathrm{SO}_{4}$} & Blank & 14.6 & 145 & 0.902 & - \\
\hline & 5 & 19.5 & 132 & 0.911 & 25.2 \\
\hline & 10 & 34.2 & 114 & 0.920 & 57.3 \\
\hline & 20 & 38.9 & 102 & 0.922 & 62.5 \\
\hline & 50 & 43.8 & 95.1 & 0.923 & 66.7 \\
\hline & 100 & 60.3 & 87.3 & 0.918 & 75.8 \\
\hline & 200 & 83.4 & 72.4 & 0.965 & 82.5 \\
\hline & 400 & 90.7 & 66.1 & 0.988 & 83.9 \\
\hline & 600 & 110 & 51.8 & 0.976 & 86.7 \\
\hline
\end{tabular}

\subsection{Potential of zero charge and the inhibition mechanism}

The dependence of double layer capacitance on the applied dc potential is graphically represented in Figure 5 in $1.0 \mathrm{M} \mathrm{HCl}$ and $0.5 \mathrm{M} \mathrm{H}_{2} \mathrm{SO}_{4}$ solutions in the absence and presence of inhibitor. The values $\mathrm{PZC}$ and $\mathrm{E}_{\mathrm{OCP}}$ (open circuit potential) for mild steel in the inhibited and uninhibited solutions of $1.0 \mathrm{M} \mathrm{HCl}$ and $0.5 \mathrm{M} \mathrm{H}_{2} \mathrm{SO}_{4}$ are shown in Table 4. The surface charge of the mild steel at the open circuit potential can be calculated using the equation,

$$
\mathrm{E}_{\mathrm{r}}=\mathrm{E}_{\mathrm{OCP}}-\mathrm{E}_{\mathrm{PZC}}
$$

where $\mathrm{E}_{\mathrm{r}}$ - Antropor's "rational" corrosion potential ${ }^{34}$.

While measuring impedance or electrical properties of a system using EIS, the region of analysis from solution side to metal surface can be reached by decreasing frequency, i.e. lower the frequency closer the region to metal surface. Thus, the impedance measured at $100 \mathrm{~Hz}$ frequency, will correspond to the region of metal solution interface. The surface charge of the mild steel at OCP was found to be positive in the inhibited and uninhibited $1.0 \mathrm{M} \mathrm{HCl}$ and $0.5 \mathrm{M}$ $\mathrm{H}_{2} \mathrm{SO}_{4}$ solutions with respect to PZC.

The hetero atoms such as $\mathrm{N}$ present in the inhibitor molecules can get protonated and will have positive charge. These positively charged inhibitor molecules can't directly approach the positively charged metal surface due to electrostatic repulsive forces. However, the anions $\left(\mathrm{Cl}^{-}\right.$and $\mathrm{SO}_{4}{ }^{2-}$ ions $)$ derived from the acids can directly get attached to the metal surface ${ }^{28}$. This indicates the adsorption of anions onto the metal surface by electrostatic attraction towards the metal surface to form first adsorption layer on the metal surface. The positively charged inhibitor molecules get attached to metal surface through the chloride and sulphate bridges.

\subsection{Adsorption isotherm}

The adsorption of dye molecules at the metal solution interface minimizes the corrosion rate and it is considered as a substitution adsorption process where an organic compound from the aqueous media displaces the water molecules associated with the surface $\left(\mathrm{H}_{2} \mathrm{O}_{\text {ads }}\right)$.

$$
\mathrm{Org}_{\text {sol }}+\mathrm{xH}_{2} \mathrm{O}_{\mathrm{ads}} \leftrightarrow \mathrm{Org}_{\mathrm{ads}}+\mathrm{xH}_{2} \mathrm{O}
$$

where ' $x$ ' is the number of water molecules replaced by the adsorption of one inhibitor molecule. The mechanism of adsorption of organic molecule on the metal surface in the corrosive media can be established using surface coverage and inhibitor efficiency.

In the present study, various adsorption isotherms were tested and it was found that the adsorption of inhibitor on the mild steel surface in acid media follows Langmuir adsorption isotherm (Figure 6), given by the expression ${ }^{35}$

$$
\mathrm{C}_{\text {inh }} / \theta=\mathrm{C}_{\text {inh }}+1 / \mathrm{K}_{\mathrm{ads}}
$$

Where $\mathrm{C}_{\mathrm{inh}}$ is the concentration of the inhibitor, $\theta$ is the surface coverage and $\mathrm{K}_{\text {ads }}$ is the equilibrium constant. The

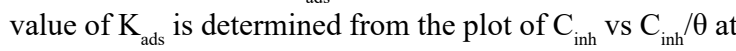



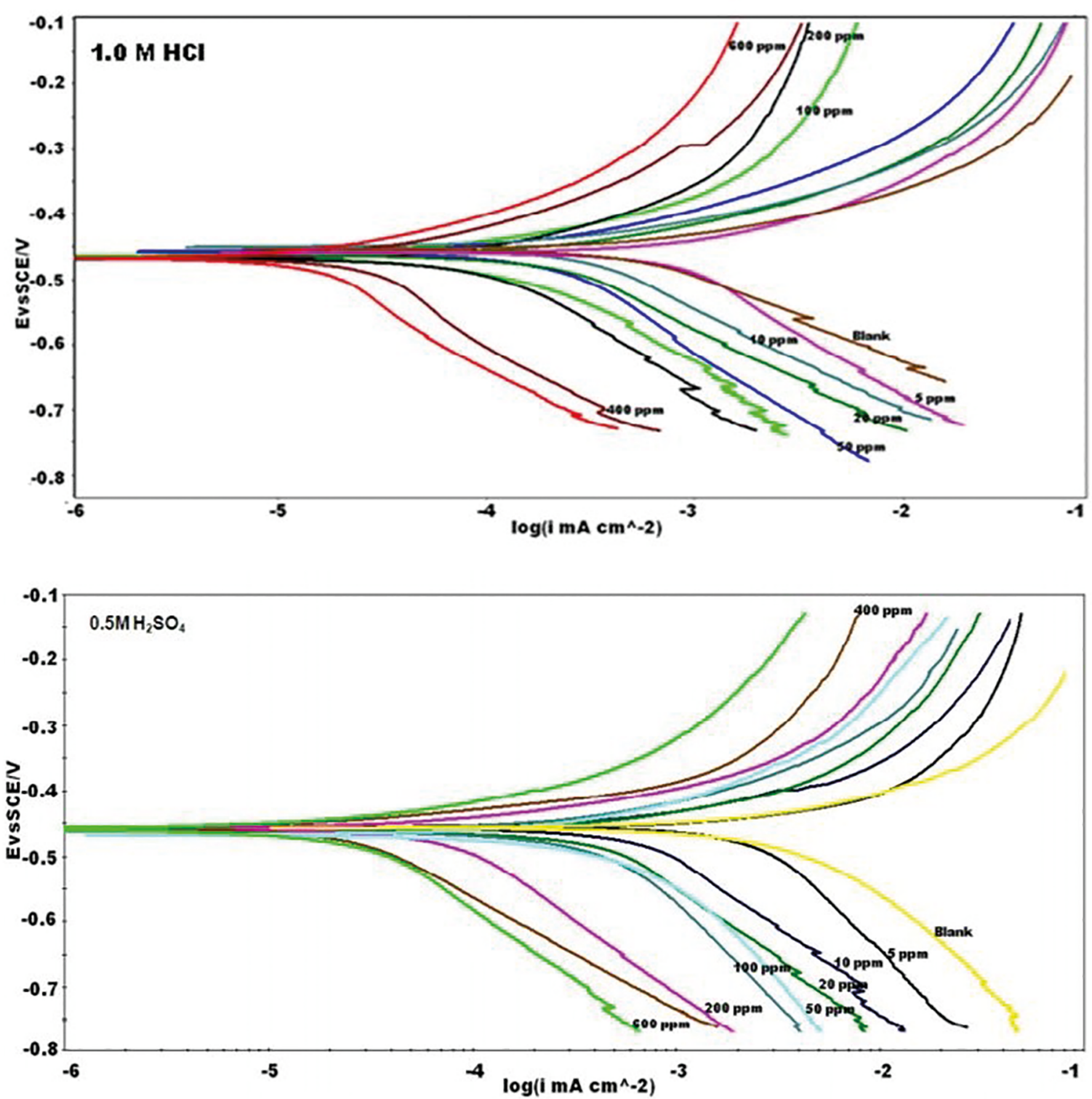

Figure 4. Potentiodynamic polarization plots recorded for $\mathrm{MS}$ electrode in $1.0 \mathrm{M} \mathrm{HCl}$ and $0.5 \mathrm{M} \mathrm{H}_{2} \mathrm{SO}_{4}$ solutions in the absence and presence of Colocid dye at various concentrations

constant temperature, which is used to calculate the value of the standard free energy of adsorption using the following expression $^{28}$

$$
\mathrm{K}_{\text {ads }}=1 / 55.5 \exp (-\Delta \mathrm{G} / \mathrm{RT})
$$

The plots obtained were linear in both the media with the correlation coefficients greater than 0.99 . The calculated values of $\Delta \mathrm{G}_{\mathrm{ads}}$ at room temperature in $1.0 \mathrm{M} \mathrm{HCl}$ and $0.5 \mathrm{M} \mathrm{H}_{2} \mathrm{SO}_{4}$ solutions are $-27.73 \mathrm{~kJ} \mathrm{~mol}^{-1}$ and $-27.98 \mathrm{~kJ}$ $\mathrm{mol}^{-1}$ respectively. The negative values of $\Delta \mathrm{G}_{\text {ads }}$ show the spontaneous adsorption of dye molecules on the metal surface. In general the value of $-\Delta \mathrm{G}_{\text {ads }}$ less than and around $20 \mathrm{kJmol}^{-1}$ represents physisorption, while the value greater than $40 \mathrm{kJmol}^{-1}$ represents chemisorptions ${ }^{28}$. If the value of $-\Delta \mathrm{G}_{\text {ads }}$ lies between $20 \mathrm{kJmol}^{-1}$ and $40 \mathrm{kJmol}^{-1}$, then it represents both physisorption and chemisorptions ${ }^{28}$. Thus in the present study the dye molecules get adsorbed on the metal surface by both by physisorption and chemisorption in the acid media studies.

\subsection{Surface morphology - SEM Analysis}

The adsorption of inhibitor molecules onto the metal surface greatly reduces the corrosive attack of the environment. Figure 7 and 8 show the surface morphologies of Iron metal in the presence and absence of inhibitor molecules in the corrosive media. From these images it can be seen that the corrosive nature of sulphuric acid is larger than that of hydrochloric acid. Presence of inhibitor greatly reduced the pits on the metal surface in both the acid environments. 
Table 3. Electrochemical parameters for $\mathrm{MS}$ in $1.0 \mathrm{M} \mathrm{HCl}$ and $0.5 \mathrm{M} \mathrm{H}_{2} \mathrm{SO}_{4}$ solutions in the presence and absence of inhibitor from potentiodynamic polarization curves.

\begin{tabular}{|c|c|c|c|c|c|c|}
\hline Medium & $\begin{array}{c}\text { Inhibitor } \\
\text { Concentration (ppm) }\end{array}$ & $\mathrm{E}_{\text {corr }}(\mathrm{mV})$ & $\mathrm{I}_{\text {corr }}\left(\mathrm{mA} \mathrm{cm}^{-2}\right)$ & $\beta_{\mathrm{c}}$ & $\beta_{\mathrm{a}}$ & $\begin{array}{c}\text { Inhibitor } \\
\text { efficiency (IE \%) }\end{array}$ \\
\hline \multirow{9}{*}{$1.0 \mathrm{M} \mathrm{HCl}$} & Blank & -452 & 1.21 & 192 & 141 & - \\
\hline & 5 & -449 & 0.716 & $` 198$ & 147 & 40.8 \\
\hline & 10 & -442 & 0.642 & 201 & 144 & 46.9 \\
\hline & 20 & -458 & 0.567 & 199 & 149 & 53.1 \\
\hline & 50 & -453 & 0.474 & 203 & 145 & 60.8 \\
\hline & 100 & -460 & 0.216 & 207 & 148 & 82.1 \\
\hline & 200 & -456 & 0.199 & 198 & 152 & 83.5 \\
\hline & 400 & -464 & 0.166 & 202 & 157 & 86.2 \\
\hline & 600 & -469 & 0.129 & 207 & 143 & 89.4 \\
\hline \multirow{9}{*}{$0.5 \mathrm{M} \mathrm{H}_{2} \mathrm{SO}_{4}$} & Blank & -458 & 2.93 & 227 & 155 & - \\
\hline & 5 & -463 & 2.165 & 218 & 161 & 26.1 \\
\hline & 10 & -465 & 1.266 & 212 & 152 & 56.8 \\
\hline & 20 & -468 & 1.089 & 215 & 151 & 62.8 \\
\hline & 50 & -472 & 1.01 & 220 & 157 & 65.7 \\
\hline & 100 & -475 & 0.738 & 216 & 152 & 74.8 \\
\hline & 200 & -461 & 0.545 & 219 & 156 & 81.4 \\
\hline & 400 & -463 & 0.501 & 224 & 161 & 82.9 \\
\hline & 600 & -459 & 0.407 & 229 & 167 & 86.1 \\
\hline
\end{tabular}
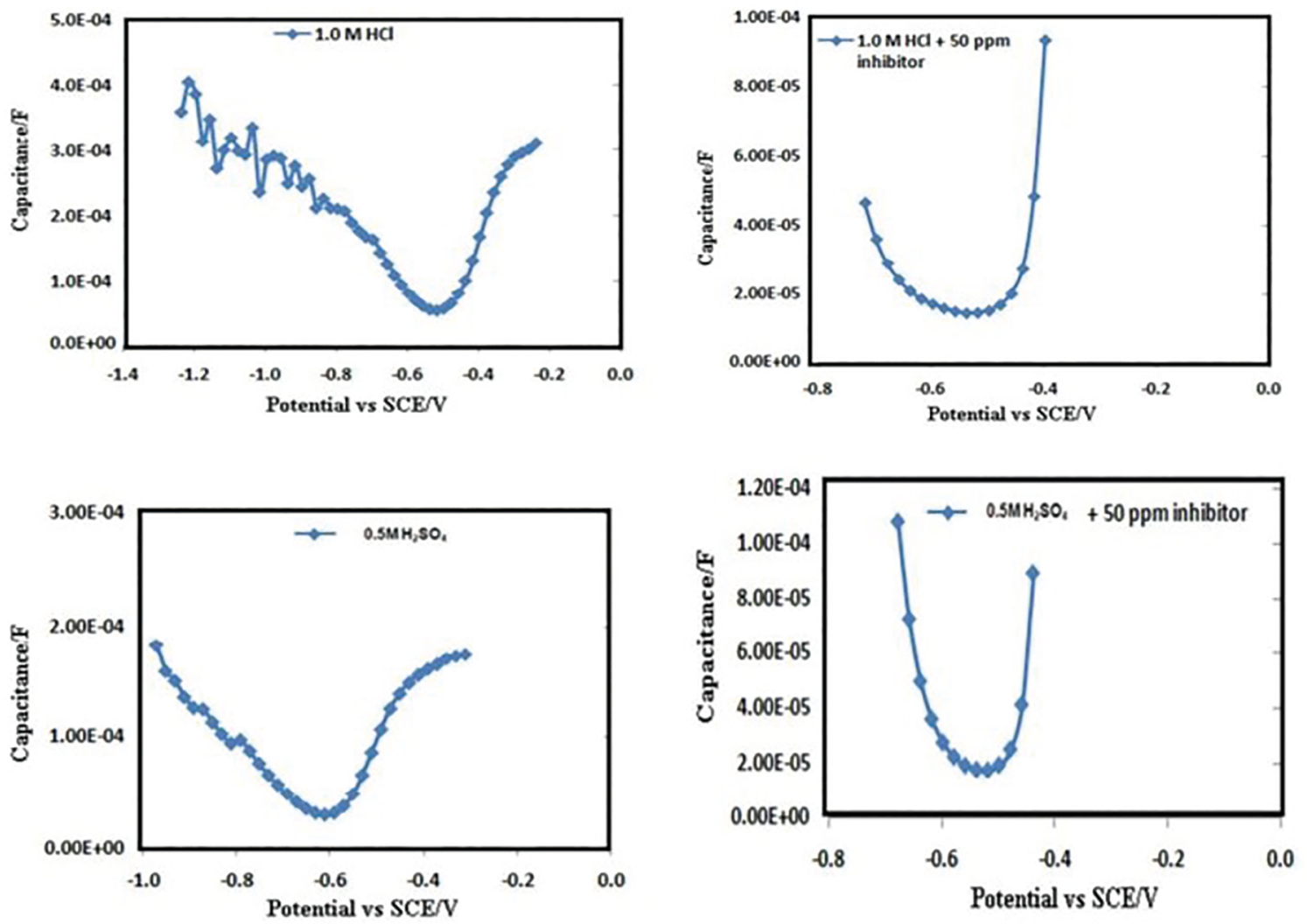

Figure 5. Plot of differential capacitance vs. applied electrode potential in $1.0 \mathrm{M} \mathrm{HCl}$ and $0.5 \mathrm{M} \mathrm{H}_{2} \mathrm{SO}_{4}$ solutions in the absence and presence of Colocid dye 
Table 4. Excess charge on $\mathrm{MS}$ electrode in $1.0 \mathrm{M} \mathrm{HCl}$ and $0.5 \mathrm{M} \mathrm{H}_{2} \mathrm{SO}_{4}$ solutions in the presence and absence of inhibitor.

\begin{tabular}{lccc}
\hline Medium & $\mathrm{E}_{\text {ocp }}(\mathrm{mV})$ & PZC $(\mathrm{mV})$ & Excess Charge \\
\hline $1.0 \mathrm{M} \mathrm{HCl}$ & -452 & -470 & + \\
$1 \mathrm{M} \mathrm{HCl}+50$ ppm of inhibitor & -462 & -510 & + \\
$0.5 \mathrm{M} \mathrm{H}_{2} \mathrm{SO}_{4}$ & -458 & -600 & + \\
$0.5 \mathrm{MH}_{2} \mathrm{SO}_{4}+50$ ppm of inhibitor & -460 & -580 & + \\
\hline
\end{tabular}

\section{$1.0 \mathrm{M} \mathrm{HCl}$}

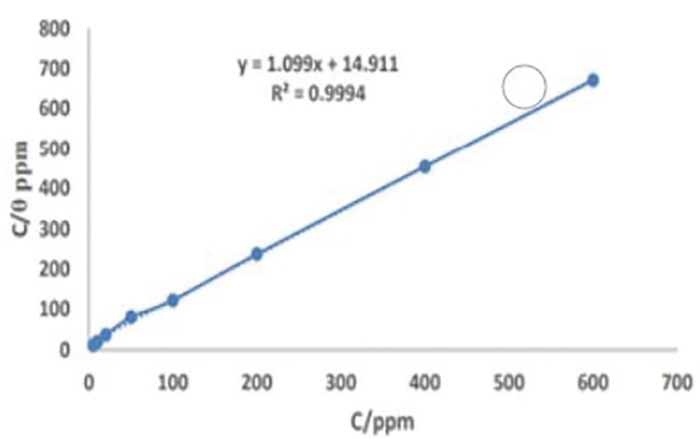

$0.5 \mathrm{M} \mathrm{H}_{2} \mathrm{SO}_{4}$

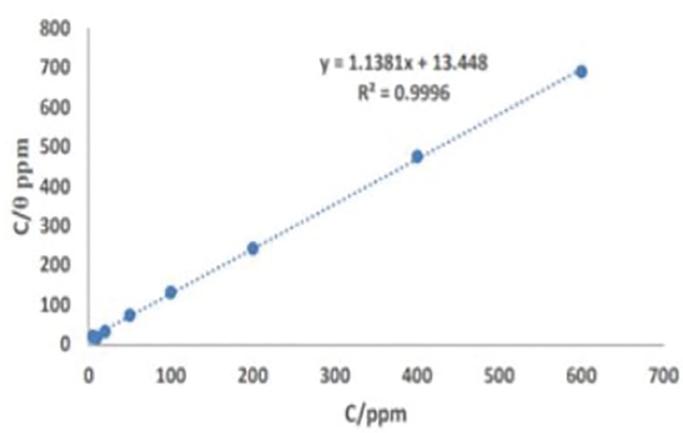

Figure 6. Langmuir adsorption isotherm for the adsorption of Colocid dye onto $\mathrm{MS}$ surface in $1.0 \mathrm{M} \mathrm{HCl}$ and $0.5 \mathrm{M} \mathrm{H}_{2} \mathrm{SO}_{4}$ solutions
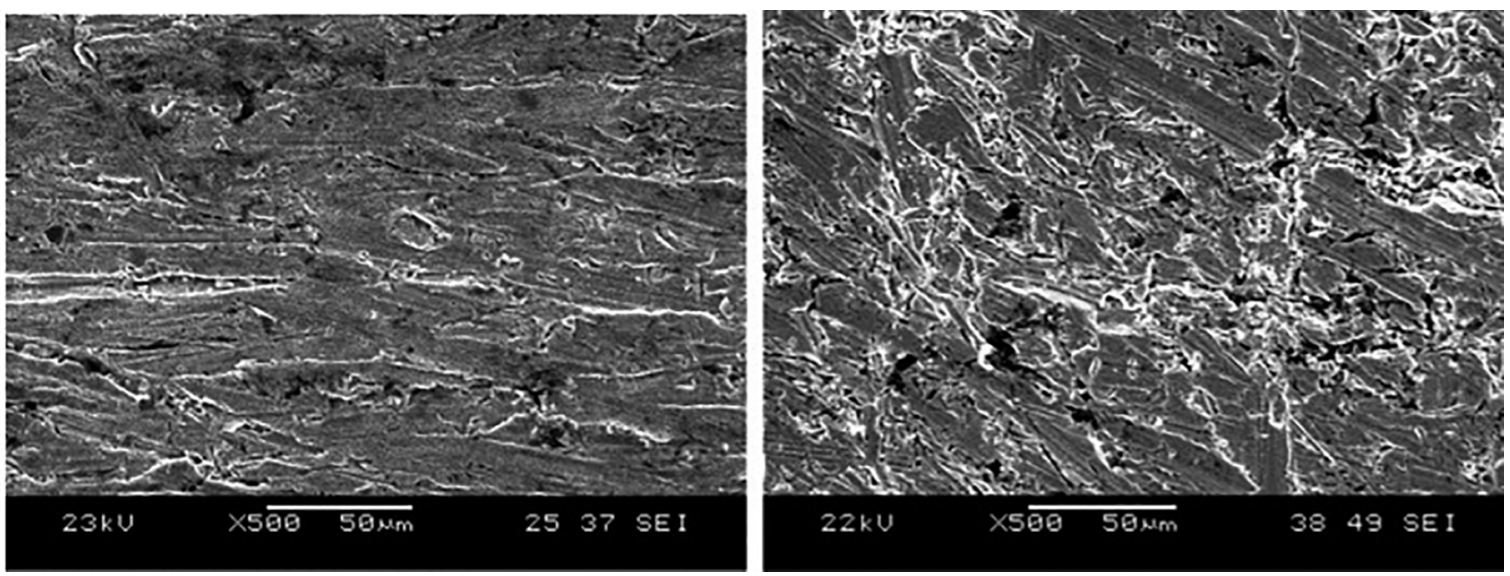

Figure 7. SEM Monographs of Iron specimen in $1.0 \mathrm{M} \mathrm{HCl}(7 \mathrm{a})$ and $0.5 \mathrm{M} \mathrm{H}_{2} \mathrm{SO}_{4}$ (7b) solutions in the absence of inhibitor

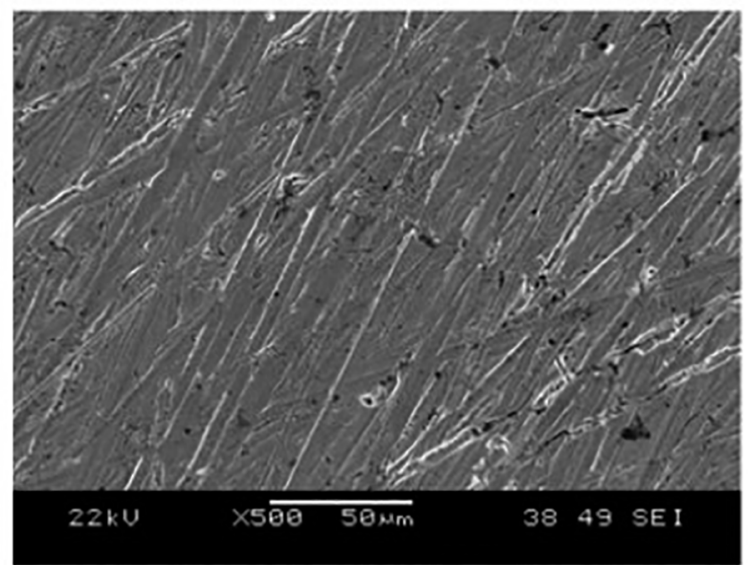

Figure.8a

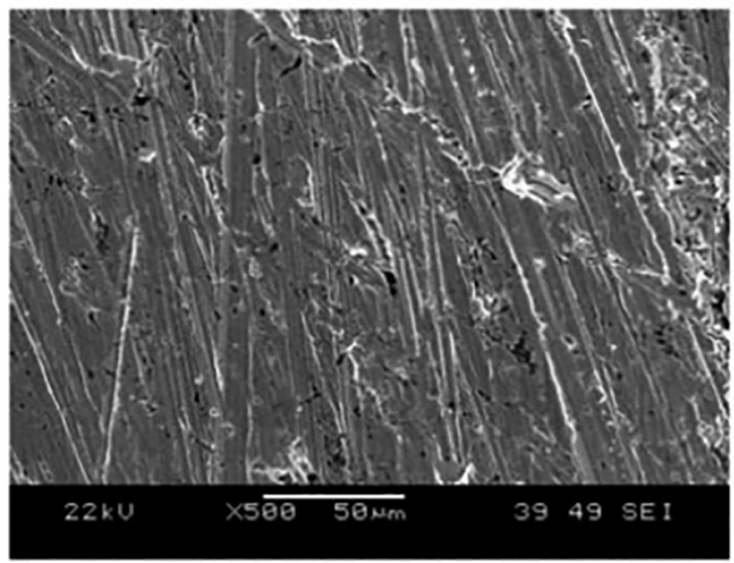

Figure.8b

Figure 8. SEM Monographs of Iron specimen in $1.0 \mathrm{M} \mathrm{HCl}(8 \mathrm{a})$ and $0.5 \mathrm{M} \mathrm{H}_{2} \mathrm{SO}_{4}$ (8b) in the presence of inhibitor caption 


\section{Conclusion}

The corrosion inhibition performance of Colocid dye on the corrosion of mild steel was compared in two acid media (1.0 M HCl and $0.5 \mathrm{M} \mathrm{H}_{2} \mathrm{SO}_{4}$ ) using weight loss and electrochemical methods. The following are the important conclusions drawn from the present study.

i In both the acid media with increase in inhibitor concentrations, the inhibition efficiency increases.

ii The maximum inhibition efficiency was observed at $600 \mathrm{ppm}$ concentration of inhibitor in both the acid media.

iii The dye molecules exhibited higher corrosion inhibition efficiency in $1.0 \mathrm{M} \mathrm{HCl}$ solution compared to $0.5 \mathrm{M} \mathrm{H}_{2} \mathrm{SO}_{4}$ solution due to the higher bridging capacity of chloride ions than sulphate ions.

iv The potentiodynamic polarization curve indicates that the dye molecule acts as a mixed type inhibitor.

$\mathrm{v}$ The adsorption of dye molecules onto the metal surface follows Langmuir adsorption isotherm.

vi The negative values of $\Delta \mathrm{G}$ indicated the spontaneous adsorption on the metal surface.

vii Studies on PZC and adsorption isotherm showed that the adsorption mechanism involves both physisorption and chemisorption in $1.0 \mathrm{M} \mathrm{HCl}$ and $0.5 \mathrm{M} \mathrm{H}_{2} \mathrm{SO}_{4}$ solutions.

\section{References}

1. Zhao Y. Corrosion and protections of Somaloy ${ }^{\circledR}$ components. [Degree Project]. Stockholm: KTH Royal Institute of Technology, Industrial Engineering and Management; 2016.

2. Oguzie EE, Li Y, Wang FH. Corrosion inhibition and adsorption behavior of methionine on mild steel in sulfuric acid and synergistic effect of iodide ion. Journal of Colloid and Interface Science. 2007;310(1):90-98.

3. Flores-De los Ríos JP, Sánchez-Carrillo M, Nava-Dino CG, Chacón-Nava JG, Escobedo-Bretado MA, Monreal-Romero HA, et al. Corrosion Inhibition of Mild Steel using Agavoideae Extract in $1 \mathrm{M} \mathrm{HCl}$ Solution. International Journal of Electrochemical Science. 2015;10:10210-10222.

4. Atta AM, El-Mahdy GA, Al-Lohedan HA, Al-Hussain SA. Corrosion Inhibition of Mild Steel in Acidic Medium by Magnetite Myrrh Nanocomposite. International Journal of Electrochemical Science. 2014;9:8446-8457.

5. Eghbali F, Moayed MH, Davoodi A, Ebrahimi N. Critical pitting temperature (CPT) assessment of 2205 duplex stainless steel in $0.1 \mathrm{M} \mathrm{NaCl}$ at various molybdate concentrations. Corrosion Science. 2011;53(1):513-522.

6. Fouda AS, Ellithy AS. Inhibition effect of 4-phenylthiazole derivatives on corrosion of $304 \mathrm{~L}$ stainless steel in $\mathrm{HCl}$ solution. Corrosion Science. 2009;51(4):868-875.

7. Moretti G, Guidi F, Grion G. Tryptamine as a green iron corrosion inhibitor in $0.5 \mathrm{M}$ deaerated sulphuric acid. Corrosion Science. 2004;46(2):387-403.
8. Olivares O, Likhanova NV, Gómez B, Navarrete J, LlanosSerrano ME, Arce E, et al. Electrochemical and XPS studies of decylamides of a-amino acids adsorption on carbon steel in acidic environment. Applied Surface Science. 2006;252(8):2894 2909.

9. Zhang DQ, Gao LX, Zhou GD. Synergistic effect of 2-mercapto benzimidazole and $\mathrm{KI}$ on copper corrosion inhibition in aerated sulfuric acid solution. Journal of Applied Electrochemistry. 2003;33(5):361-366.

10. Oguzie EE, Unaegbu C, Ogukwe CN, Okolue BN, Onuchukwu AI. Inhibition of mild steel corrosion in sulphuric acid using indigo dye and synergistic halide additives. Materials Chemistry and Physics. 2004;84(2-3):363-368.

11. Shibli SMA, Saji VS. Co-inhibition characteristics of sodium tungstate with potassium iodate on mild steel corrosion. Corrosion Science. 2005;47(9):2213-2224.

12. $\mathrm{Mu} \mathrm{G}, \mathrm{Li} \mathrm{X}$. Inhibition of cold rolled steel corrosion by Tween-20 in sulfuric acid: weight loss, electrochemical and AFM approaches. Journal of Colloid and interface Science. 2005;289(1):184-192.

13. Feng Y, Siow KS, Teo WK, Hsieh AK. The synergistic effects of propargyl alcohol and potassium iodide on the inhibition of mild steel in $0.5 \mathrm{M}$ sulfuric acid solution. Corrosion Science. 1999;41(5):829-852.

14. Tang L, Mu G, Liu G. The effect of neutral red on the corrosion inhibition of cold rolled steel in $1.0 \mathrm{M}$ hydrochloric acid. Corrosion Science. 2003;45(10):2251-2262.

15. Tang L, Li X, Mu G, Li L, Liu G. Synergistic effect between 4-(2-pyridylazo) resorcin and chloride ion on the corrosion of cold rolled steel in $0.5 \mathrm{M}$ sulfuric acid. Applied Surface Science. 2006;252(18):6394-6401.

16. Oguzie EE. Influence of halide ions on the inhibitive effect of congo red dye on the corrosion of mild steel in sulphuric acid solution. Materials Chemistry and Physics. 2004;87(1):212-217.

17. Oguzie EE. Corrosion inhibition of mild steel in hydrochloric acid solution by methylene blue dye. Materials Letters. 2005;59(8-9):1076-1079.

18. Ebenso EE, Okafor PC, Ibok UJ, Ekpe UJ, Onuchukwu AI. The joint effects of halide ions and methylene blue on the corrosion inhibition of aluminium and mild steel in acid corrodent. Journal of Chemical Society of Nigeria. 2004;29(1):15-25

19. Ebenso EE. Effect of halide ions on the corrosion inhibition of mild steel in $\mathrm{H} 2 \mathrm{SO} 4$ using methyl red: Part 1. Bulletin of Electrochemistry. 2003;19(5):209-216.

20. Ebenso EE. Effect of methyl red and halide ions on the corrosion of aluminum in $\mathrm{H} 2 \mathrm{SO} 4$ center: Part 2. Bulletin of Electrochemistry. 2004;20(12):551-559.

21. Peme T, Olasunkanmi LO, Bahadur I, Adekunle AS, Kabanda MM, Ebenso EE. Adsorption and corrosion inhibition studies of some selected dyes as corrosion inhibitors for mild steel in acidic medium: gravimetric, electrochemical, quantum chemical studies and synergistic effect with iodide ions. Molecules. 2015;20(9):16004-16029 
22. Oguzie EE, Okolue BN, Ogukwe CE, Unaegbu C. Corrosion inhibition and adsorption behaviour of bismark brown dye on aluminium in sodium hydroxide solution. Materials Letters. 2006;60(28):3376-3378.

23. Ebenso EE, Oguzie EE. Corrosion inhibition of mild steel in acidic media by some organic dyes. Materials Letters. 2005;59(17):2163-2165.

24. Oguzie EE, Okolue BN, Ebenso EE, Onuoha GN, Onuchukwu AI. Evaluation of the inhibitory effect of methylene blue dye on the corrosion of aluminium in hydrochloric acid. Materials Chemistry and Physics. 2004;87(2-3):394-401.

25. ASTM International. ASTM G31 - Standard Practice for Laboratory Immersion Corrosion Testing of Metals. West Conshohocken: ASTM International; 1999.

26. Ashassi-Sorkhabi H, Shaabani B, Seifzadeh D. Effect of some pyrimidinic Shciff bases on the corrosion of mild steel in hydrochloric acid solution. Electrochimica Acta. 2005;50(1617):3446-3452.

27. Li X, Deng S, Li N, Xie X. Inhibition effect of bamboo leaves extract on cold rolled steel in $\mathrm{Cl} 3 \mathrm{CCOOH}$ solution. Journal of Materials Research and Technology. 2017:6(2):158-170.

28. Mallaiya K, Subramaniam R, Srikandan SS, Gowri S, Rajasekaran N, Selvaraj A. Electrochemical characterization of the protective film formed by the unsymmetrical Schiff's base on the mild steel surface in acid media. Electrochimica Acta. 2011;56(11):3857-3863.
29. Goyal M, Yadav O, Kumar R, Sharma RK, Singh G. Experimental, surface characterization and computational evaluation of the acid corrosion inhibition of mild steel by methoxycarbonylmethyltriphenylphosphonium bromide (MCMTPPB). Indian Journal of Chemical Technology. 2017;24(3):256-268.

30. Fonseca C, Barbosa MA. Corrosion behaviour of titanium in biofluids containing $\mathrm{H} 2 \mathrm{O} 2$ studied by electrochemical impedance spectroscopy. Corrosion Science. 2001;43(3):547-559.

31. Behpour M, Ghoreishi SM, Gandomi-Niasar A, Soltani N, Salavati-Niasari M. The inhibition of mild steel corrosion in hydrochloric acid media by two Schiff base compounds. Journal of Materials Science. 2009;44(10):2444-2453.

32. Benabdellah M, Touzani R, Aouniti A, Dafali A, El Kadiri $\mathrm{S}$, Hammouti B, et al. Inhibitive action of some bipyrazolic compounds on the corrosion of steel in $1 \mathrm{M} \mathrm{HCl}$ : Part I: Electrochemical study. Materials Chemistry and Physics. 2007;105(2-3):373-379.

33. Prabhu RA, Venkatesha TV, Shanbhag AV, Praveen BM, Kulkarni GM, Kalkhambkar RG. Quinol-2-thione compounds as corrosion inhibitors for mild steel in acid solution. Materials Chemistry and Physics. 2008;108(2):283-289.

34. Popova A, Sokolova E, Raicheva S, Christov M. AC and DC study of the temperature effect on mild steel corrosion in acid media in the presence of benzimidazole derivatives. Corrosion Science. 2003;45(1):33-58.

35. Rahiman AFSA, Sethumanickam S. Corrosion inhibition, adsorption and thermodynamic properties of poly (vinyl alcohol-cysteine) in molar $\mathrm{HCl}$. Arabian Journal of Chemistry. 2017;10(Suppl 2):S3358-S3366. 